\title{
Inter-relating factors influencing the quality of stay of Chinese-speaking students in a French University
}

\author{
Lee Hsin-I ${ }^{1} \cdot$ Lin Tzu-Yu ${ }^{2} \cdot$ Chiu Sheng-Hsiung ${ }^{2}$ \\ Accepted: 18 May 2021/ Published online: 22 May 2021 \\ (C) The Author(s), under exclusive licence to Springer Nature B.V. 2021
}

\begin{abstract}
This paper explores factors that influenced the quality of stay of Chinese-speaking mobile students in France, as the living experience abroad is one of the most-cited difficulties for international students. For practicality, we sieve through previous researches to identify 20 factors (grouped into 4 Dimensions: Personal Dimension Teacher's Effectiveness Dimension, Campus Environment Dimension, and Daily Environment Dimension), which most likely correlated with the quality of the stay of mobile Chinese-speaking students in France. We adopt the DANP (DEMATEL-based ANP) model, i.e., combining the Decision Making and Trial Evaluation Laboratory (DEMATEL) method and the Analysis Network Process (ANP), to construct the Influential Network Relation Maps, identifying the hierarchical structure among the factors and the dimensions. We find that the "Teacher's Effectiveness" is the most influential dimension to the other 3 dimension. Our research can provide more insights on the French educational system improvement, and help define a more effective policy strategy focus.
\end{abstract}

Keywords Chinese-speaking mobile student · Quality of students' stay · Academic mobility · Analysis Network Process · Decision Making and Trial Evaluation Laboratory · DANP

Chiu Sheng-Hsiung

mika.bear0809@gmail.com

Lee Hsin-I

Hsini.Lee79@gmail.com

Lin Tzu-Yu

blackmallows@gmail.com

1 School of Foreign Languages, Guilin Tourism University, No. 26 Liangfeng Road, Yanshan District, Guilin 541006 Guangxi, China

2 Accounting School, Nanfang College Guangzhou, No. 882, Wenquan Road, Conghua District, Guangzhou 510970 Guangdong, China 


\section{Introduction}

International students have always been an important talent pool, even more critically so due to economic globalization and trade liberalization (Arkoudis et al., 2019; Heng, 2019; MurphyLejeune, 2003a). Asian students are increasingly joining the study abroad trend leading to growing concerns over the impacts of the host countries' academic environments on these international Asian students, of which the Chinese students occupy a considerable proportion (Ramburuth \& McCormick, 2001; Wang \& Hannes, 2014; Wong, 2004).

According to statistics of Campus France (2019), student mobility has seen a rising trend over the past ten years: in 2017, there were 5.1 million students worldwide studying abroad (excluding language and short stays), representing a $28 \%$ increase in five years; by 2025, the number should reach 9 million. Contending with this global phenomenon, major host countries $^{1}$ are constantly improving their offers in order to attract more foreign students. Among them, France, as the top non-English speaking host country, has worked on mending the gaps in the reception policies to maintain this distinctive status. However, there are still issues in its international student policies, of which the most frequent are the visa policy, the administrative procedures upon arrival, lack of uniformity of the reception programs. These issues are especially visible in contrast to its neighbors' practices such as those of the UK and northern European countries. The absence of a consistent practice toward foreign students has fueled a sense of isolation, particularly for non-francophone ones. In order to build a more welcoming environment for foreign students and thus attract more students into the country, France has to look into ways of improving the reception policies. In response, the Prime Minister announced, in November 2018, a new strategy called "Bienvenue en France - Choose France" and focusing on two main objectives: (1) to offer better reception conditions, such as simplification of visa processing, ease of student housing, increased availability of scholarships, etc. and (2) to make French education visible to the world. To fine-tune policies to accommodate international students in France, one must first understand the factors that influence the quality of the stay and academic performance of foreign students. The perceived quality of living and academic environment vary, at least in three aspects: (1) the student's own characteristics, which include country of origin, age, previous study experiences, cultural identity, proficiency in the host country's language, financial resources, etc.; (2) the daily experiences such as length of stay, and his/her view of the host country's institutional, political, legal, and social environment; (3) the interpersonal interactions among peers, teaching and administrative staff, and locals.

Among the international students encountering the above-mentioned difficulties in France, we are particularly interested in Sinophone students. This was in part in response to the 2014 French government announcement ${ }^{2}$, indicating that the number of Chinese-speaking students will continue to increase, forming the largest foreign student community in France. According to MESRI-SIES ${ }^{3}$ statistics, the number of students arriving in France in the 2019-2020 academic year, China is only second behind Morocco, a country with historical ties to France. Although this growth might now be interrupted by the COVID-19 epidemic, this is still an

\footnotetext{
${ }^{1}$ Top ten host countries in order of ranking: US, UK, Australia, France, Germany, Russia, Canada, China, Japan, and Italy (UNESCO database: extracted January 2018 by Campus France).

2 Announced by Mathilde Mallet, Head of Asia at Campus France (French agency for the promotion of higher education, reception and international mobility).

${ }^{3}$ MESRI-SIES: Ministry of Higher Education and Research and Innovation - information systems and statistical studies.
} 
inevitable trend in the long run. To make Chinese-speaking students feel more welcome in France, it is important to understand the factors that affect their stays first. There has been a pool of researches exploring the overseas study experience of Chinese students (Heng, 2019; Meng et al., 2018), and/or their satisfaction during their stays (Merola et al., 2019; PerezEncinas et al., 2020; Yu \& Wright, 2016), yet most of the researches have focused on the English-speaking environment, and only very few on foreign students in France (Hartwell \& Ounoughi, 2019), let alone Chinese students. To accurately evaluate the circumstances faced by Chinese-speaking students in France, we first sieve through literature to define the factors that influence their lives there the most. We reckon that there are many factors that affect the quality of foreign students studying abroad: in addition to language barriers, international students are subject to various cultural, educational and psychological adaptation processes, which are all interdependent. Most previous research, however, has only focused on one single study area, e.g., linguistics, psychology, or cross-cultural studies, while ignoring the interrelations among different influencing factors. (Heng, 2019; Meng et al., 2018; Wang et al., 2012; Zhang \& Brunton, 2007; Zhou \& Todman, 2009). To make up for this gap, we use the DANP (DEMATEL-based ANP) method to establish the inter-dependent relations among these influencing factors. The DANP (DEMATEL-based ANP) method is the combination of the Decision-Making Trial and Evaluation Laboratory (DEMATEL) method, where the interdependent features of different factors can be used to adjust the influential weights, based on the basic concept of the analytical network process (ANP) (Hsu et al., 2012). With deeper and more thorough understanding of the factors that affect Chinese-speaking students' lives in France, decision makers can prioritize and evaluate the relating policies more efficiently. By examining the reciprocal relationships among factors influencing the quality of stay of Chinese-speaking students in French universities, we hope to expand the literature for studying-abroad experiences, particularly for Chinese students' in a non-English-speaking environment. Using systematic analysis, we construct a hierarchy framework of factors, and thus to help re-focus French reception policies for Chinese-speaking students, and shed new light on how to ameliorate the quality of their stays and academic success.

\section{Literature review}

One of the main goals for students studying abroad is to pursue better educational opportunities and to achieve academic success. Studies have shown that the quality of the stay plays an important role of influencing international students' academic performance (CastielloGutiérrez et al., 2020; Merola et al., 2019; Nieto \& Zoller Booth, 2010; Zhang \& Brunton, 2007). Combing through previous literature, we define the 20 factors that influence international students' quality of stays in the host country into 4 dimensions: Personal, Teacher, Campus Environment and Daily Environment.

\section{Factors affect quality of stay of international students}

\section{1) Personal dimension}

Personal factors are one of the important factors that affect the quality of international students studying abroad in the host country, and often affect their academic and daily life. According to Jones (2017), in addition to the international student's own personality, other features such 
as the entourage, family background, and mother country culture help shape academic and social experiences during the stay. A student's social and biographic profile impact future experiences when interacting with another culture. In this context, Nieto and Zoller Booth (2010) defined the ability to understand and improve relationships across cultures the "cultural competence," where being more culturally competent meant one can integrate into the new environment better. Other studies also indicated that factors like a student's socio-economic status in the home country, as well as the national, institutional or family resources were directly related to the success in international students (Cao et al., 2016; Heng, 2019; Jones, 2017; Murphy-Lejeune, 2003a). Among them, "family resources" played an important role in the destination chosen, the quality of the accommodation and academic facilities, as well as the range of relational, social or cultural activities (e.g., whether the student participates in a paid activity). Academic performance was too affected by personal factors, such as the students' own learning ability, family background, experience with different cultures, and sense of responsibility for their studies (Heng, 2019; Wong, 2004; Young et al., 2013; Zhang \& Brunton, 2007; Zhou \& Todman, 2009). The language barrier in the learning environment has a certain effect on all international students in their studies, daily life and cultural exchange. Misunderstandings of cultural or academic codes are especially common to those with limited language skills and/or difficulty in perceiving cultural differences, which might lead to stress, anxiety, and/or lack of interaction with classmates or supervisors (Cao et al., 2016; Ryan \& Viete, 2009; Yu \& Wright, 2016; Zhang \& Brunton, 2007). Some studies suggested the impact on foreign students in non-English-speaking countries was stronger (Wang \& Hannes, 2014; Wang \& Lin, 2019). Different learning methods between international students and native students also need to be considered (Cao et al., 2016; Ramburuth \& McCormick, 2001; Wang et al., 2012; Wong, 2004). For example, international students might need more encouragement to be spontaneous in learning, to participate classroom discussions, writing papers, and develop critical thinking (Yu \& Wright, 2016). Indeed, some scholars have noted that Chinese students' learning attitudes are still under the influence of Confucianism, and that they are more passive in learning, relying heavily on recitation to learn (Turner, 2006; Wang \& Lin, 2019).

\section{2) Teacher's effectiveness dimension}

From previous studies, we find that for international students, the process of integration into the university life depends heavily on teachers and the student-teach relations. The studentteach relations not only can be affected by the students' language ability and/or cultural thension (Guinamard \& Colin, 2012; Yu \& Wright, 2016), but whether there is sufficient support from the teachers, and/or the teaching methods. Studies have shown that the a teacher's "enthusiasm," along with mental and/or mentor support, could ensure effective teaching and motivation, and had the potential to improve the quality of international students studying abroad for better integrating (Kunter et al., 2008; Merola et al., 2019; Murray, 1983; Yu \& Wright, 2016). We later define these attributes of teachers as "personal dispositions" in this study. Compared with other international students, Chinese students are more used to a hierarchic relation between teachers and students, under the Confucianism, and the expectation towards the teachers are quite different from that in Western education; as a result, Chinese mobile students have a greater adaptation gap to fill (Turner, 2006; Wang \& Lin, 2019). In a study of Hartwell and Ounoughi (2019), with a sample of 1900 international students in France, the authors suggested that students with teachers who encourage more participation in 
the classroom integrated better in the new environment. There are a number of studies indicating that teaching methods are influential to the quality of students studying abroad (Kember, 2000; Perez-Encinas et al., 2020). For Chinese-speaking mobile students, one of the challenges is adapting to the pedagogy of the host country, sometimes even lead to anxiety issues (Durnerin et al., 2019; Kember, 2000; Wu, 2015). Perez-Encinas et al. (2020) reviewed studies from 167 countries, and highlighted that the enthusiasm of teachers, teaching tools or teaching methods played key roles in adaptation of foreign mobile students.

\section{3) Campus environment dimension}

While many local students will find interactions with administrations, classmates, and teachers in a university environment familiar, foreign students from countries with different academic practices will likely find that these daily tasks require extra work to decode implicit cultural and/or academic rationales (Durnerin et al., 2019; Meng et al., 2018; Paivandi, 2016; Wang \& Hannes, 2014). Researches showed that administrative assistances can help students with academic adaptation issues (Robertson et al., 2000; Wang \& Hannes, 2014), ranging from the utilization of school facilities to overcome academic challenges (Yu \& Wright, 2016). As Perez-Encinas et al. (2020) pointed out, equipment/facilities (tangible and intangible resources) provided by the schools also played important roles for students in choosing the destination to study in. Once on campus, proper administrative assistances can help international students to better understand academic expectations in advance (Merola et al., 2019). In previous researches, many had also pointed out the weakness in school administration system in France, particularly for foreign students (Claeys, 1999; Cohen, 2001; Coulon \& Paivandi, 2003; Wang, 2012). In contrast, Chinses administrative student services are very different from other countries, as there is usually a centralized, one-stop administration assistant system. For instance, the "Fu Dao Yuan" provides comprehensive cares on campus, covering all levels of daily life, learning status, moral education and even mental health care (Liu \& Lin, 2016). In addition, Chinese campus administration often provides reminders for registrations, payments due dates, etc. So for Chinese students study in a host country with a more spontaneous learning system, they may need more time to get used to the campus administrations. Other campus factors, like organizing various student events/activities can also help international students to accumulate "social capitals," providing cross-cultural exchange opportunities (Merola et al., 2019). Similarly, if there are more group learnings/discussions in the classroom, it can make international students social and academic integration, adapt to the teaching method, improve academic ability, and better foreign language ability. Better relationships with classmates can also help on a student's psychological level, alleviate stress, loneliness, homesickness, and isolation (Merola et al., 2019; Wu, 2015; Yu \& Wright, 2016).

\section{4) Daily environment dimension}

A significant amount of research has found that the living and study conditions of international students, as well as their adaptability, e.g., the degrees of sociability with locals, their attitude toward different culture and foreign life, etc., also play an important role in the success of the student's academic experience (Coulon \& Paivandi, 2003; Meng et al., 2018; MurphyLejeune, 2003b; Young et al., 2013; Zhang \& Brunton, 2007). According to Perez-Encinas et al. (2020), the different types of international students have different concerns. For international graduate students, social life, living expenses, and city characteristics are all important. 
As for international undergrad students, they tend to value city offering more. When choosing where to study, Asian students in Australia pay more attention to the safety of the country or region (Merola et al., 2019). International students tend to feel lonely and have a strong desire to meet members of the host community. Studies have pointed out that socializing with others helps to relieve tensions and psychological problems stemming from loneliness (Robertson et al., 2000; Wang \& Hannes, 2014; Yu \& Wright, 2016; Zhang \& Brunton, 2007). Interaction with locals is highly important to facilitate socio-cultural adaptation. Research results also show that international students in Australia feel that the adaptation to local life takes up a larger proportion in the integration process (Yu \& Wright, 2016). Jones (2017) pointed out that host countries should address issues relating to support services, e.g., health insurance, accommodation policy, community security. Note that the complexity and cumbersome administrative procedures in France are notorious not only to foreigners but also to the French. This would also add to further hindrance to students. Cao et al. also pointed out that among Chinese students in the six countries of the EU, those who stay in France encounter more problems on a daily basis than those who are in England (2016).

\section{DANP model application}

Research on the reciprocal effects among factors, the quality of stay of International students or Chinese-speaking students in France remains thin on the ground. In addition to filling this research gap, we also hope to provide a holistic view on foreign students' studying experiences in France, particularly for Chinese-speaking mobile students, by exploring the different factors' mutual influences and their possible hierarchical structure.

DANP model is the combination of DEMATEL and ANP methods, and has been widely applied to solve a variety of multiple-criteria decision making problems, such as e-learning evaluations (Tzeng et al., 2007), selection of manufacturing industries (Hsu et al., 2012), estore business's consumers' shopping behavior (Chiu et al., 2013), or the stock selection problem (Shen et al., 2014). Unlike traditional analysis methods, which commonly assume independent and equally-weighted factors, under the framework of the DANP model, we are able to assess the in-model relations among the influential factors in the model (Tzeng et al., 2007).

\section{Data and methodology}

\section{Measures}

The quality of foreign students' stays is determined by many factors as settling in a foreign country leads to multiple changes, including physical, psychological, cultural and social. This paper intended to identify factors that most influence the quality of the stay of Chinesespeaking mobile students in France. We first comb through relevant literature, in English and in French, to find the common denominators in researches that correlates with the quality of the stay of mobile Chinese language students in France. From previous studies, we are able to identify 20 factors, which we grouped into 4 dimensions: Personal Dimension (P), Teacher's Effectiveness Dimension (T), Campus Environment Dimension (C) and Daily Environment Dimension (E), in order to evaluate various policies/services offered to foreign students. The description of these variables is shown in Table 1. 
Table 1 Dimensions and factors influencing the quality of studying abroad

\section{(P) Personal Dimension Key micro-factors influencing international students}

p1. Family background

p2. Family financial support

p3. Language proficiency

p4. Previous experience abroad

p5. Learning method

(T) Teacher's Effectiveness Dimension

t1. Teacher/student relationship

t2. Personal dispositions of teachers

t3. Teaching tools

t4. Teaching methods

t5. Dimensions of the contents

t6. Organisation and clarity

t7. Evaluation mode

(C) Campus Environment Dimension

c1. Teaching equipment

c2. Administrative assistances

c3. Relationships with classmates

(E) Daily environment Dimension

e1. Location of the city

e2. Administrative Process

e3. Housing

e4. Health care

e5. Interpersonal

communication
Family environment, parents' expectations, educational principles

Financial capacity of the family

Level of practice of the language of the host country

Previous experiences with other cultures

Ways of learning

Major macro-factors related to teachers influencing international students

Interaction between student and teacher during studies

Taking into account the diverse needs of students to adapt their pedagogy, their teaching methods. Self-assessment

Devices used by the teacher to provide courses

Ways to organize the teaching activity in order to make students learn

Course Volume and Content

Teach in a structured and clear way

Methods or means used to assess student work

Key institutional macro-factors influencing students

Equipment (tangible and intangible resources) provided by the establishment Reception of foreign students to facilitate integration (orientations, administrative support for academic studies and/or campus lives, etc.)

Interaction between students

Major macro-factors related to daily life that influence students

Geographic Location, size, security, amenities of the host city

All administrative processes to be carried out during the student stay

Environment, comfort, cost, etc.

Physical and mental health; easy access to care

Interactions with others (neighbours, comrades, friends, etc.)

\section{Procedure and analyses}

DEMATEL was first developed by the Banelle Memorial Institute in Geneva, in 1972, to solve complex mixing and decision-making problems in the laboratory. DEMATEL can identify reciprocal relationships, and thus construct a hierarchical framework of variables. DEMATEL has been used to evaluate various scenarios, from marketing strategies to group decisionmaking capacities. It has also been successfully applied to evaluate educational institutions and teachers in Taiwan. In this research, we use the ANP method to determine the links among the dimensions that influenced the quality of study abroad and hence likelihood of success of foreign students in France. Through this analysis, we can also rank the dimensions by importance.

Using DANP model, we are able to quantify complex human behavior in a more logical way, thereby identifying important factors, which may help decision markers adjust policies to better meet foreign students' need. There are two steps in constructing the analytical framework of evaluation (Yang \& Tzeng, 2011): (1) build an Influential Network Relation Map (INRM) depending upon the total influence matrix of factors and dimensions using the DEMATEL technique; (2) calculate the weights of each factor. Using the DANP method, 
we were able to further explore the interaction and interdependence among different categories and factors of the empirical cases. The process of DANP model is briefly illustrated in Fig. 1.

\section{Participants and survey method}

The DANP model is used to identify the reciprocal effects between the factors of the quality of Chinese students' stay in France. Unlike traditional statistical methods, the DANP questionnaire requires only experts in the relevant fields as participants (Chiu et al., 2013; Shen et al., 2014).

Our study involves 16 "experts" (5 men, 11 women) from eight different higher education institutions in mainland China and Taiwan in seven different departments in Social Science and Humanities, as listed in Table 2. There were $14 \mathrm{PhD}$ students and $2 \mathrm{PhD}$ who have supported research for less than one year. Note that the participants were also selected according to certain factors, such that they were representative of the demographic characteristics relevant to the Chinese student population in France, i.e., they all have at least four years of experience in French higher education, are a doctoral student and/or have completed more than two cycles of studies in France. We deemed them "experts" as they were with more experiences in the host country, comparing to newly arrived students, and would understand more thoroughly the needs of international students. This sampling strategy was to capture the heterogeneity of the population in both the host and mother countries, in order to evaluate the magnitude of the studying abroad phenomenon.

We conducted face-to-face interviews with these "experts," using an expert questionnaire where the interviewees are asked to rate the effect and influence of each factor, pair-wisely, from zero (completely non-influential) to four (extremely influential).

\section{Analytical structure}

We applied the DANP analytical framework to the quantified results of the aforementioned evaluation survey, in order to assess the relations among the dimension/factors that quality of

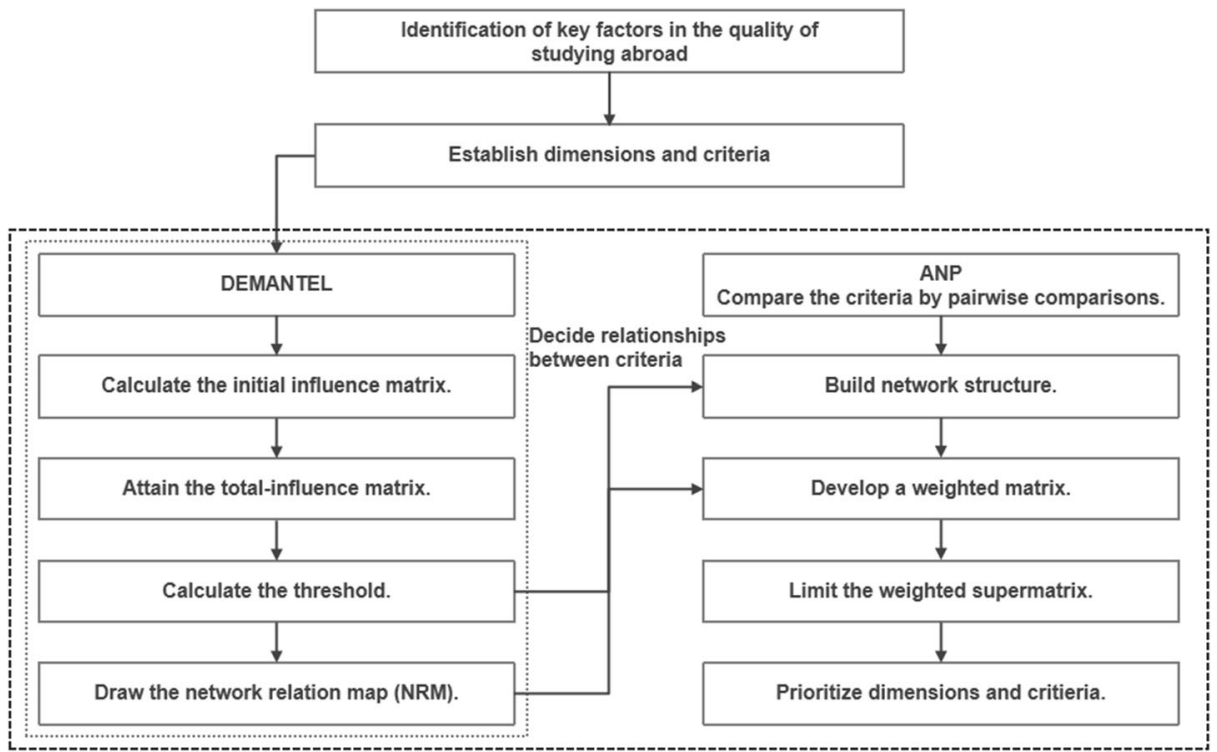

Fig. 1 The DANP process 
Table 2 Sociodemographic details of participants $(n=16)$

Sociodemographic variable

Frequency $(n=16)$

\begin{tabular}{ll} 
Age (years) & 7 \\
$28-30$ & 3 \\
$31-33$ & 6 \\
$34-36$ & 5 \\
Gender & 11 \\
Male & \\
Female & 5 \\
Duration of stay (years) & 9 \\
$\leq 4$ & 2 \\
$5-10$ & \\
$\geq 11$ & 7 \\
Type of institution & 9 \\
Grande école & \\
University & 2 \\
Level of current or previous education in France & 11 \\
Bachelor + Master + PhD student & 2 \\
Master + PhD student & 1 \\
PhD student + PhD & \\
PhD student & \\
Research areas (current or former) & \\
Art & 5 \\
Commerce and management & 1 \\
History & 8 \\
Literature & 2 \\
Educational Sciences & 6 \\
Language Sciences & 6 \\
Philosophy & 3 \\
\hline
\end{tabular}

a This refers to the participants' research areas (current or former) when studying in France. Some of them have studied in different areas in different stages of education.

stay to Students with Chinese-speaking in French university. The total coefficients of influences of each dimension and factor based on the section of Measures are summarized in Table 3. The symbol D is used to represent the degree of influence of a dimension/factor on others, while $\mathrm{R}$ represents the influenced degree of a dimension/factor by others. $\mathrm{D}+\mathrm{R}$ (i.e., prominence) demonstrates the total degree of connection among dimensions or factors, meaning that a dimension/factor with higher value of $\mathrm{D}+\mathrm{R}$ has a stronger relationships with other dimensions/factors, and vice versa. In addition, D-R (cause relation) shows the degree of causality among dimensions or factors, indicating that a dimension/factor with higher value of $\mathrm{D}-\mathrm{R}$ have a greater influence on the other dimensions/factors, and vice versa.

\section{Results and discussion}

\section{Relationship analysis}

From Table 3, we can see that the Teacher's Effectiveness Dimension has the largest D-R value (0.45), meaning it is the most influential dimension. We can then infer that, when designing policies to improve the quality of stay for Chinese-speaking students, the priority should be given factors in the Teacher's effectiveness. On the other hand, the value of Personal 
Table 3 Coefficients of influences: influences given and received of dimensions and factors

\begin{tabular}{|c|c|c|c|c|}
\hline Dimensions/factors & $\mathrm{D}$ & $\mathrm{R}$ & $\mathrm{D}+\mathrm{R}$ & D-R \\
\hline (P) Personal Dimension & 1.13 & 1.91 & 3.04 & -0.78 \\
\hline p1. Family background & 0.07 & 0.02 & 0.09 & 0.05 \\
\hline p2. Family financial support & 0.08 & 0.02 & 0.10 & 0.06 \\
\hline p3. Language proficiency & 0.12 & 0.15 & 0.27 & -0.02 \\
\hline p4. Previous experience abroad & 0.07 & 0.05 & 0.12 & 0.02 \\
\hline p5. Learning method & 0.05 & 0.09 & 0.14 & -0.03 \\
\hline (T) Teacher's Effectiveness Dimension & 1.42 & 0.97 & 2.38 & 0.45 \\
\hline t1. Teacher-student relationships & 0.05 & 0.09 & 0.14 & -0.03 \\
\hline t2. Teachers' enthusiasm & 0.06 & 0.05 & 0.12 & 0.01 \\
\hline t3. Teaching devices & 0.05 & 0.05 & 0.09 & 0.00 \\
\hline t4. Teaching modes & 0.07 & 0.05 & 0.12 & 0.01 \\
\hline t5. Course density & 0.04 & 0.03 & 0.07 & 0.00 \\
\hline t6. Organization and clarity & 0.04 & 0.04 & 0.08 & 0.00 \\
\hline t7. Evaluation mode & 0.03 & 0.03 & 0.06 & 0.01 \\
\hline (C) Campus Environment Dimension & 1.31 & 1.01 & 2.32 & 0.30 \\
\hline c1. Teaching equipment & 0.04 & 0.02 & 0.06 & 0.03 \\
\hline c2. Administrative assistances & 0.04 & 0.02 & 0.06 & 0.01 \\
\hline c3. Relationships with classmates & 0.05 & 0.07 & 0.12 & -0.02 \\
\hline (E) Daily Environment Dimension & 0.79 & 0.75 & 1.54 & 0.04 \\
\hline e1. Location of the city & 0.05 & 0.04 & 0.10 & 0.01 \\
\hline e2. Administration process & 0.02 & 0.05 & 0.07 & -0.02 \\
\hline e3. Housing & 0.03 & 0.07 & 0.10 & -0.04 \\
\hline e4. Health care & 0.02 & 0.04 & 0.06 & -0.02 \\
\hline e5. Interpersonal communication & 0.05 & 0.08 & 0.14 & -0.03 \\
\hline
\end{tabular}

Dimension has the largest $\mathrm{D}+\mathrm{R}$ value (3.04), meaning it has the strongest correlation with other dimensions.

We use the values of $\mathrm{D}+\mathrm{R}$ and $\mathrm{D}-\mathrm{R}$ in Table 3 to draw the Importance-Relation diagram, i.e., the INRM, where the horizontal axis is $\mathrm{D}+\mathrm{R}$ (the prominence) and the vertical axis is $\mathrm{D}-\mathrm{R}$, the degree of causality, for dimensions (Fig. 2), and for factors within each dimension (Figs. 3, $4,5,6)$. The INRMs provide visualizations to the relations among those dimensions/factors. We then proceed to explain our findings.

\section{Relationships among dimensions}

From Fig. 2, we can see that dimension $T$ has the highest $\mathrm{D}-\mathrm{R}$ value, meaning that it has the influential effects on other dimensions: $\mathrm{C}, \mathrm{E}, \mathrm{P}(\mathrm{T} \rightarrow\{\mathrm{C} \mathrm{E} \mathrm{P}\})$; dimension C's D-R value is higher than that of $\mathrm{E}$ and $\mathrm{P}$, meaning that $\mathrm{C}$ has the influential effects on dimensions $\mathrm{E}$ and $\mathrm{P}$ $(\mathrm{C} \rightarrow\{\mathrm{E} \mathrm{P}\})$; and Dimension $\mathrm{E}$ is influential to Dimension $\mathrm{P}(\mathrm{E} \rightarrow\{\mathrm{P}\})$, as Dimension $\mathrm{E}$ has a higher D-R value. Understanding these influential relations will enable instructors and the government to consider the overall situation more effectively when making decisions. For example, improving the Teacher's effectiveness may of great benefit to catalyze the improvements of how students feel about the Campus environment, the daily environment and other personal Dimension. We observe that Dimension T (Teacher's effectiveness), has the predominating impact on the quality of Chinese-speaking mobile students' study experience in France (a more in-depth discussion on this can be found in the next section). This means that the variables in this dimension, such as a teacher's characteristics, teaching pedagogy, teacherstudent relationship, etc., played an important role in affecting all other factors. Contrary to 


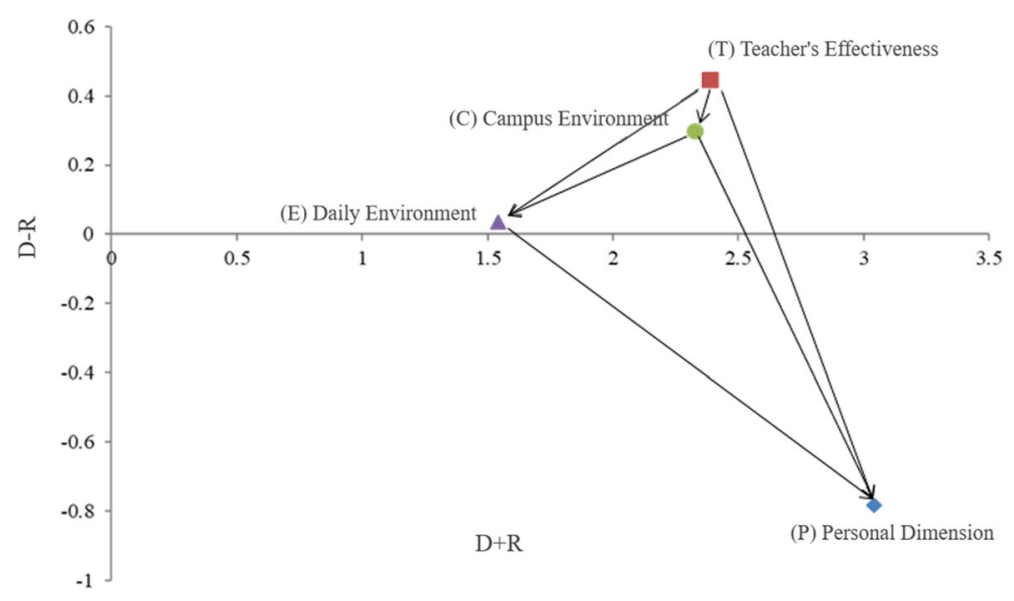

Fig. 2 "Importance-relation" diagram

previous studies that focused primarily on reception policy or language skills, our study shows that teacher-related factors deserve more attention than other institutional or personal factors, in relation to the quality of stay of mobile Chinese-speaking students in France.

\section{Relationship among factors}

In this section, with the help of the "importance-relationship" diagram for each dimension, we explore factors in more details. The following Figs. 3, 4, 5, and 6 are the visualized results for the relations among factors in the same dimension, where the horizontal axis D + R represents the "degree of relation," and the vertical axis D - R represents the "degree of influence."

\section{Teacher effectiveness $(\mathrm{T})$}

The relations among factors in Teacher's Effectiveness dimension are depicted in the INRM Fig. 3. We observed that the factor $t 4$ has the highest $D-R$ value, meaning it affects factor $\mathrm{t} 2, \mathrm{t} 7$,

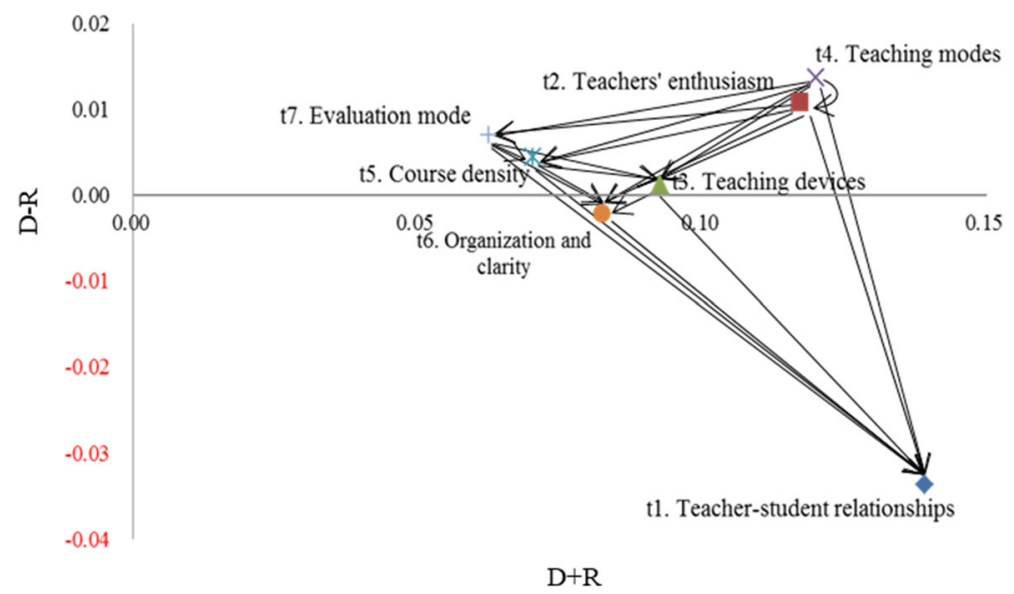

Fig. 3 Teacher effectiveness (T) 


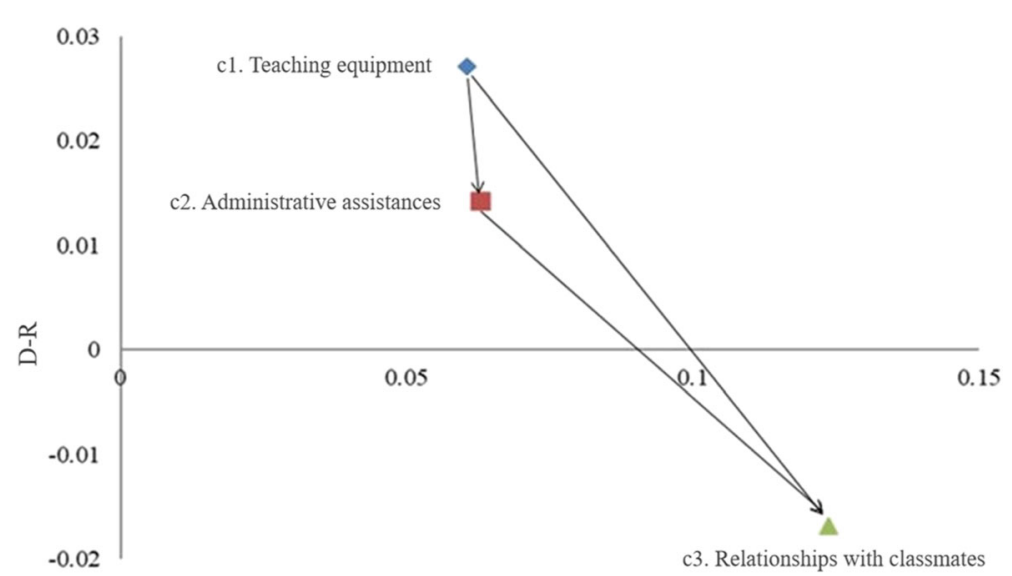

$\mathrm{D}+\mathrm{R}$

Fig. 4 Campus environment (C)

$\mathrm{t} 5, \mathrm{t} 3$, $\mathrm{t} 6$, and $\mathrm{t} 1 \mathrm{t} 4 \rightarrow\{\mathrm{t} 2 \mathrm{t} 7 \mathrm{t} 5 \mathrm{t} 3 \mathrm{t} 6 \mathrm{t} 1\})$; and so on so forth. Factors with higher D-R values, like 4 (teaching method) and 2 (teacher's enthusiasm) in this dimension, are more likely to be the influencers. Although $\mathrm{tl}$ (teacher-student relationship) is the most important factor in this Dimension, it is also the only one that is dominated by other factors. We propose some explanations to these observations:

a) About $\mathrm{t} 4$, the educational and cultural experience of Chinese students in the motherland is the core of the question, as the Sinophone pedagogy is very different from that of the western world. Bathed in a teacher-centered teaching context, Chinese students are more used to the high collectivist and power distance culture (Cao et al., 2016). Obedience to the teacher and silence unless asked to speak are common practices in the Chinese educational culture. Under the circumstances, it is often challenging for Chinses students to be more independent and spontaneous in the quest of knowledge, as they begin studying abroad, especially in the Western countries, where there is less "spoon-feeding" of knowledge by the teachers (Wong, 2004). In China, teachers' lectures are most likely to be simply repeating information from the supplementary materials. In France, however,

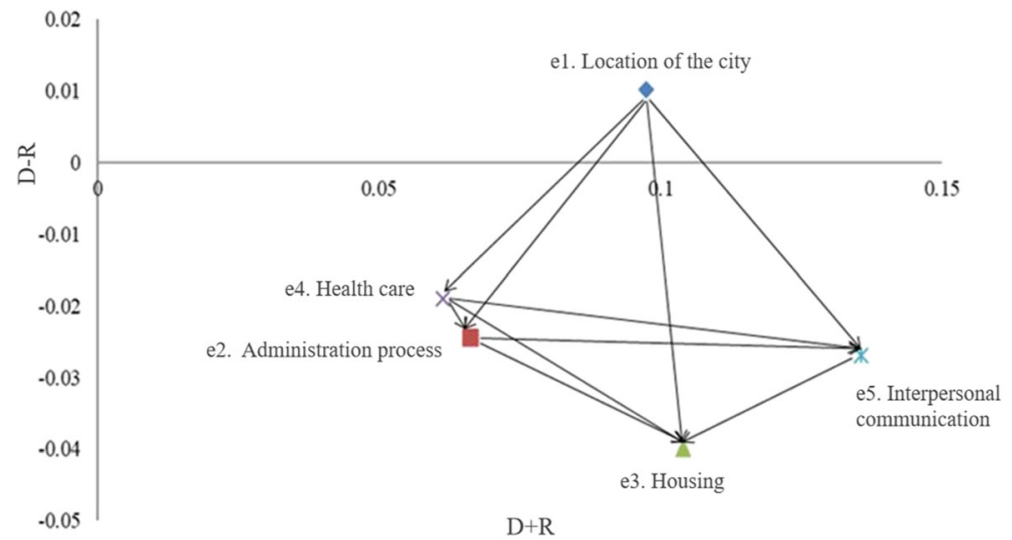

Fig. 5 Daily environment (E) 


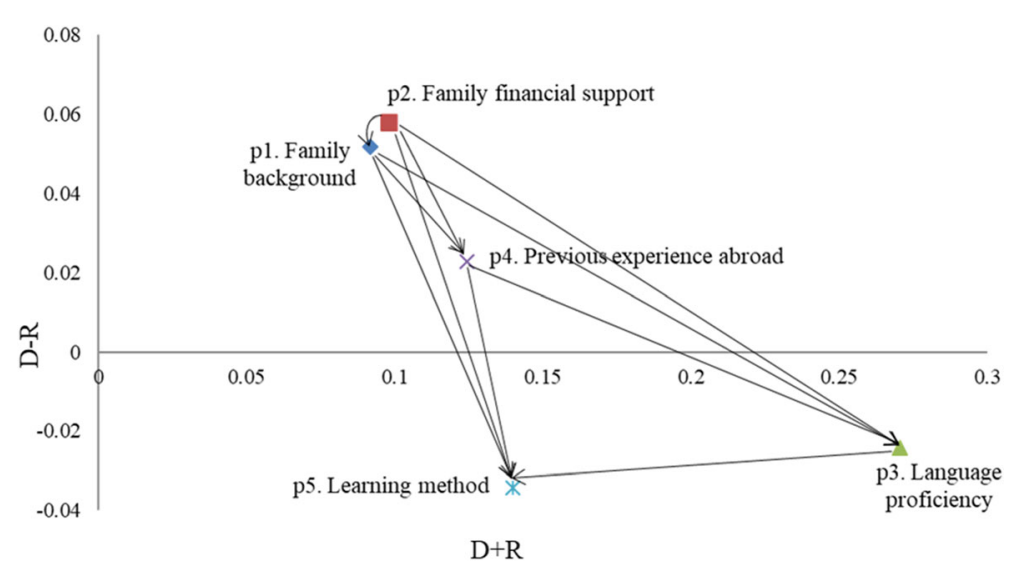

Fig. 6 Personal dimension (P)

teachers offer more insights on the course subjects, as well as encouraging critical thinking. This fundamental difference in learning processes could explains why, in the eyes of the expert interviewees, the French teaching method could be seen as a major influencer. Furthermore, for newcomers, the time and effort required adapting to the new teaching method, and the problems that may be caused by inadaptability include other parts that directly affect learning outcomes or extend to physical and mental health.

b) About t2, we claim that the role played by teachers is also crucial in the adaptation process for foreign students. This is also in coherence with previous studies: In 2010, Nieto \& Zoller established that teachers with a high level of intercultural sensitivity are more likely to help international students, making them feel more welcomed in the host country. For a better adaptation of Asian students in Australia, Wong (2004) asserted that better relationship between the teacher and the student would promote better mutual understanding, and raise teachers' awareness of cultural diversity in the classrooms, such that the teacher would take these differences into account when planning courses. Wang et al. (2012) identified the features that an "ideal teacher" would possess. These features, also called a teacher's "personal attributes," include the abilities to accommodate pedagogically to various needs of students and to construct proper relationship with students. Wang also found that Chinese students valued these features more than French students did. This might be attributed to the fact that students had different expectations for teachers in France and in China. That is, in addition to a teacher's "energy" or "enthusiasm," the way a teacher communicates knowledge directly influences the motivation and desire to learn. In that sense, our study suggested that French teachers could pay more attention to this aspect when interacting with Chinese students, so that they may build a better environment for efficient teaching and learning.

c) About $\mathrm{t} 1$, in previous literature, the aspect of "teacher-student relationship" had been seen as a very important factor in the success of learning. Nevertheless, this relationship is much less studied in higher education than in a primary school setting (Hagenauer et al., 2016; Hagenauer \& Volet, 2014). While our research showed consistent results with previous studies, we have also found that this "teacher-student relationship" was most likely to be affected by all other factors in this dimension, i.e., $\{\mathrm{t} 4 \mathrm{t} 2 \mathrm{t} 7 \mathrm{t} 5 \mathrm{t} 3 \mathrm{t} 6\}$.

2. Campus environment $(\mathrm{C})$ 
The quantified results for the "importance-relationship" in the Campus Environment dimension are illustrated in Fig. 4. We observed that the factor $\mathrm{c} 1$ has the highest value of D-R, meaning it affects factor $\mathrm{c} 2$ and $\mathrm{c} 3(\mathrm{c} 1 \rightarrow\{\mathrm{c} 2 \mathrm{c} 3\})$. That is, In Dimension $\mathrm{C}, \mathrm{c} 1$ (teaching equipment) is most likely to affect the others; it included both the tangible and intangible resources provided by the institution. As most of the researches on satisfaction surveys have shown, resources on campus plays an important role in the studying abroad decision process (Hartwell \& Ounoughi, 2019; Perez-Encinas et al., 2020; Robertson et al., 2000; Yu \& Wright, 2016). In other words, to improve the the quality of Chinese-speaking students in France, the first thing to consider should be updating the teaching equipment, which might have as cascading effect on other campus environment factors.

About c2, unlike the French educational system, micromanagement is common in Chinese education, from moral to institutional, administrative, and the intellectual aspect (cf. the system Fu Dao Yuan). It was natural, then, in the eyes of Chinese students staying in France, that the French institutions seemed to neglect their frequent demands and problems they encountered. An example is the lack of information on the functioning of education system, and this also paints an inferior image of a poorly organized and disintegrated system. In the 2014 study by Wang \& Hannes, Asian students called for institutions in their host countries to provide more administrative assistances (e.g., detailed orientation programs providing information pertaining to course selection, university facilities and campus life such as student organizations) to improve the quality of the stay.

3. Daily environment (E)

Figure 5 is the visualization of relations among factors in the Daily environment Dimension (Dimension E), in which we can see that factor el has the highest D-R value, meaning that it is most likely to affect other factors in this dimension (e $1 \rightarrow\{$ e 4 e 2 e 5 e 3$\})$. Factor e1 (location of the city) includes qualities such as the geographic location, size, security, amenities of the host city. Indeed, for a foreign student, the first question in the studying-abroad decision would often be "which city is the best to live in." For students, the first indicator of the overall ranking of French cities is always the attractiveness, following by employment opportunity, quality of life, housing, transportation network, cultural access, etc. Some relevant French organizations (Campus France ${ }^{4}$ ) are also very concerned about the attractiveness of each city to international students. From our research, nonetheless, if we want to improve the quality of Chinese students studying abroad, within the Daily Environment Dimension, governments should also first make the city itself more attractive, i.e., improve features like the security and/or amenities of the host city, followed by e4 (health care), e2 (administrative Process), e5 (interpersonal communication), and e3 (housing).

It is worth mentioning that there were several aspects in the "health care" factor (e4), including accessibility to health institutes, the administrative procedures for medical consultations, as well as psychological health issues which might be resulted from isolation, stress and pressure associated with studies. Even though a student could use an "intermediary," i.e., a person who assisted a foreign student to communicate with the physician (for the student might not master all medical vocabulary as needed), for Chinese students, oftentimes it was too intimidating to talk about their medical/psychological issues with others (for they were afraid

${ }^{4}$ The 2020-2021 awards for student cities: https://www.campusfrance.org/fr/le-palmares-2020-2021-des-villesetudiantes 
of embarrassment, or "losing face"). This could explain part of the issue in this particular "health care" factor.

\section{Personal dimension $(\mathrm{P})$}

Figure 6 is the visualized relations among factors in the Personal Dimension (Dimension P). We can see that the factor $\mathrm{p} 2$ is of the higher value of $\mathrm{D}-\mathrm{R}$, meaning it is the predominant factor in this dimension, affecting factor $\mathrm{p} 1, \mathrm{p} 4, \mathrm{p} 3$ and $\mathrm{p} 5(\mathrm{p} 2 \rightarrow\{\mathrm{p} 1 \mathrm{p} 4 \mathrm{p} 3 \mathrm{p} 5\})$. While the $\mathrm{p} 3$ (Language proficiency) and p5 (Learning method) are factors often mentioned in literature in this Dimension, the research results show that they are more likely to be affected by other factors.

According to our interviewees, a family with more financial means tend to offer its members more opportunities to travel abroad and to learn foreign languages, which affect one's later experience when studying abroad; the other important factor is family wealth, which plays a big part of the equation of study-work balance, as well as the opportunities to participate in social and cultural immersive activities. Jones (2017) noted that family financial support influenced the learning experiences of all international students. Chinese students with fewer financial resources in the United States also reported that they experienced some degree of impact on their inter-relationships (Heng, 2019).

\section{Conclusion}

Our research is motivated by filling the gap in the literature, considering the lack of research on Chinese international students in non-English higher education. This research can help decision-makers to understand the circumstances faced by Chinese-speaking students better, and to reflect on existing international student reception strategies, service redesign and management optimizations. From our model, we suggest that factors in the Teacher's Effectiveness Dimension should be given priority. It is not only international students who need intercultural skills, but also university professors. There are several ways to work on this point: to raise teachers' awareness to international students' integrations, that students sitting in the classrooms are no longer of a single nationality and that they do not have a common «culture»; to understand the "needs" of students, and adjust the pedagogy to accommodate those needs. Previous research on the factors in the Campus Environment Dimension has focused on Institutional aid and Relationships with classmates, and our study also confirms that support services are very important to the quality of stay. In addition, what Chinese students think is particularly important is the equipment (tangible and intangible resources) provided by the institutions. The relevant factors such as location, size, security, amenities of the host city and so on often mentioned in previous studies are also regarded as the most important factor by Chinese students in Daily Environment dimension. However, we also highlight that health care related issues deserve more attention from French decision-makers.

Although this research yielded some new findings, we must also note some limitations in our study. The uneven distribution of the disciplines of the interviewees, this may affect the generalization of the research results. In future research, we recommend to use a representative sample to reflect the foreign student population in the host country, in terms of fields of study. This model could also be extended to include subjects who interact with foreign students, such as professors, administrative personals, and/or other students. 
Despite these limits, our research has drawn attention to the interrelations among the 20 factors influencing the quality of stay of Chinese international students, and we can infer that providing trainings related to the factors that affect foreign students (such as teaching method, communication skills, etc.) could reduce the stress of studying abroad. By investigating the different aspects that affect the academic life of foreign students, we may better understand the variation of the factors influencing the quality of the stay and the relationships among factors. As more Chinese-speaking mobile students flow into foreign countries pursuing degrees, it is also in the government's best interest to adjust and improve its overall environment, in order to attract and retain more talents. In sum, by identifying the hierarchical structure of different factors, we helped to define the strategy focus, as well as to make evident the difficulties of the French higher education offer.

Author contribution Higher Education

Funding This work was supported by Guilin Tourism University [Grant number KQ2002].

Data availability Not applicable

Code availability Not applicable

\section{Declarations}

Competing interests The authors declare no competing interests.

\section{References}

Arkoudis, S., Dollinger, M., Baik, C., \& Patience, A. (2019). International students' experience in Australian higher education: can we do better? Higher Education, 77(5), 799-813.

Campus France (2019). Chiffres clés 2019. Available at: https://www.campusfrance.org/fr/ressource/chiffrescles-2019. Accessed 16 February 2020.

Cao, C., Zhu, D. C., \& Meng, Q. (2016). An exploratory study of inter-relationships of acculturative stressors among Chinese students from six European union (EU) countries. International Journal of Intercultural Relations, 55, 8-19.

Castiello-Gutiérrez, S., Hoye, K. A., García, H. A., \& McNaughtan, J. (2020). Educators, not bureaucrats: how managerial professionals at international student services centers engage in job crafting and create meaning in their work. Studies in Higher Education, 1-16.

Chiu, W. Y., Tzeng, G. H., \& Li, H. L. (2013). A new hybrid MCDM model combining DANP with VIKOR to improve e-store business. Knowledge-Based Systems, 37, 48-61.

Claeys, A. (1999). Welcoming foreign students to France: commercial issue or educational priority? Les documents d'information-Assemblée nationale, (1806).

Cohen, E. (2001). An action plan to improve the reception of foreign students in France: Diagnosis and proposals. Rapport au Ministre de l'éducation nationale et au Ministre des affaires étangères, 19.

Coulon, A. \& Paivandi, S. (2003). Foreign students in France: the state of knowledge. Rapport pour L'Observatoire national de la Vie Etudiante (OVE), University of Paris 8.

Durnerin, J., Laurini, R., Lee, H. I., Lemaignan, C., Livian, Y., Moreau, P., \& Parpette, C. (2019). The university Francophonie: eleven years of practice in the Auvergne Rhône Alpes region. 〈halshs-02161922〉

French government (2018). Attractiveness strategy for international students. Available at: https://ressources. campusfrance.org/agence_cf/institutionnel/fr/Dossier_presse_Strategie_attractivite_etudiants internationaux_fr.pdf Accessed 28 August 2020. 
Guinamard, I., \& Colin, S. (2012). Combating academic failure: a first experimental year of peer-to-peer tutoring at the Institute of Education and Training Sciences and Practices. Poiésis - Revista do Programa de PósGraduação em Educação, 5(0), 138-148.

Hagenauer, G., \& Volet, S. E. (2014). Teacher-student relationship at university: an important yet underresearched field. Oxford Review of Education, 40(3), 370-388.

Hagenauer, G., Gläser-Zikuda, M., \& Volet, S. E. (2016). University Teachers' Perceptions of Appropriate Emotion Display and High-Quality Teacher-Student Relationship: Similarities and Differences across Cultural-Educational Contexts. Frontline Learning Research, 4(3), 44-74.

Hartwell, L. M., \& Ounoughi, S. (2019). Expanding the comfort zones: Divergent practices of host and international university students. European Journal of Higher Education, 9(4), 377-392.

Heng, T. T. (2019). Understanding the heterogeneity of international students' experiences: A case study of Chinese international students in US universities. Journal of Studies in International Education, 23(5), 607623.

Hsu, C. H., Wang, F. K., \& Tzeng, G. H. (2012). The best vendor selection for conducting the recycled material based on a hybrid MCDM model combining DANP with VIKOR. Resources, Conservation and Recycling, $66,95-111$.

Jones, E. (2017). Problematising and reimagining the notion of 'international student experience'. Studies in Higher Education, 42(5), 933-943.

Kember, D. (2000). Misconceptions about the learning approaches, motivation and study practices of Asian students. Higher Education, 40(1), 99-121.

Kunter, M., Tsai, Y. M., Klusmann, U., Brunner, M., Krauss, S., \& Baumert, J. (2008). Students' and mathematics teachers' perceptions of teacher enthusiasm and instruction. Learning and Instruction, 18(5), $468-482$.

Liu, W., \& Lin, X. (2016). Meeting the Needs of Chinese International Students. Journal of Studies in International Education, 20, 357-370.

Meng, Q., Zhu, C., \& Cao, C. (2018). Chinese international students' social connectedness, social and academic adaptation: The mediating role of global competence. Higher Education, 75(1), 131-147.

Merola, R. H., Coelen, R. J., \& Hofman, W. H. A. (2019). The Role of Integration in Understanding Differences in Satisfaction Among Chinese, Indian, and South Korean International Students. Journal of Studies in International Education, 23(5), 535-553.

Murphy-Lejeune, E. (2003a). Student mobility and narrative in Europe: The new strangers. Routledge.

Murphy-Lejeune, E. (2003b). An experience of interculturality: Student travellers abroad. Intercultural Experience and Education, 101-113.

Murray, H. G. (1983). Low-inference classroom teaching behaviors and student ratings of college teaching effectiveness. Journal of Educational Psychology, 75(1), 138.

Nieto, C., \& Zoller Booth, M. (2010). Cultural competence: Its influence on the teaching and learning of international students. Journal of Studies in International Education, 14(4), 406-425.

Perez-Encinas, A., Rodriguez-Pomeda, J., \& de Wit, H. (2020). Factors influencing student mobility: a comparative European study. Studies in Higher Education, 1-14.

Paivandi, S. (2016). How students appreciate their learning environment?. In Giret, J.-F., Van de Velde, C. \& Verley, É.. (Eds). Student Lives. Trends and Inequalities (pp.117-132). La Documentation française.

Ramburuth, P., \& McCormick, J. (2001). Learning diversity in higher education: A comparative study of Asian international and Australian students. Higher Education, 42(3), 333-350.

Robertson, M., Line, M., Jones, S., \& Thomas, S. (2000). International students, learning environments and perceptions: A case study using the Delphi technique. Higher Education Research and Development, 19(1), 89-102.

Ryan, J., \& Viete, R. (2009). Respectful interactions: Learning with international students in the Englishspeaking academy. Teaching in Higher Education, 14(3), 303-314.

Shen, K. Y., Yan, M. R., \& Tzeng, G. H. (2014). Combining VIKOR-DANP model for glamor stock selection and stock performance improvement. Knowledge-Based Systems, 58, 86-97.

Tzeng, G. H., Chiang, C. H., \& Li, C. W. (2007). Evaluating intertwined effects in e-learning programs: A novel hybrid MCDM model based on factor analysis and DEMATEL. Expert Systems with Applications, 32(4), $1028-1044$.

Turner, Y. (2006). Chinese students in a UK business school: Hearing the student voice in reflective teaching and learning practice. Higher Education Quarterly, 60(1), 27-51.

Wang, J. J. (2012). Causes of failure in learning French by Chinese students in France: Qualitative and quantitative multifactorial study based on interviews and questionnaires, Phd thesis, University of Lorraine.

Wang, J., \& Lin, J. (2019). Traditional Chinese views on education as perceived by international students in China: International student attitudes and understandings. Journal of Studies in International Education, 23(2), 195-216. 
Wang, Q., \& Hannes, K. (2014). Academic and socio-cultural adjustment among Asian international students in the Flemish community of Belgium: A photovoice project. International Journal of Intercultural Relations, 39, 66-81.

Wang, Y., Harding, R., \& Mai, L.-W. (2012). Impact of cultural exposure on young Chinese students' adaptation in a UK business school. Studies in Higher Education, 37(5), 621-639.

Wong, J. K. K. (2004). Are the Learning Styles of Asian International Students Culturally or Contextually Based? International Education Journal, 4(4), 154-166.

Wu, Q. (2015). Re-examining the "Chinese learner": a case study of mainland Chinese students' learning experiences at British Universities. Higher Education, 70(4), 753-766.

Yang, J. L., \& Tzeng, G. H. (2011). An integrated MCDM technique combined with DEMATEL for a novel cluster-weighted with ANP method. Expert Systems with Applications, 38(3), 1417-1424.

Young, T. J., Sercombe, P. G., Sachdev, I., Naeb, R., \& Schartner, A. (2013). Success factors for international postgraduate students' adjustment: exploring the roles of intercultural competence, language proficiency, social contact and social support. European Journal of Higher Education, 3(2), 151-171.

Yu, B., \& Wright, E. (2016). Socio-cultural adaptation, academic adaptation and satisfaction of international higher degree research students in Australia. Tertiary Education and Management, 22(1), 49-64.

Zhang, Z., \& Brunton, M. (2007). Differences in living and learning: Chinese international students in New Zealand. Journal of Studies in International Education, 11(2), 124-140.

Zhou, Y., \& Todman, J. (2009). Patterns of adaptation of Chinese postgraduate students in the United Kingdom. Journal of Studies in International Education, 13(4), 467-486.

Publisher's note Springer Nature remains neutral with regard to jurisdictional claims in published maps and institutional affiliations. 